\title{
Percutaneous Coronary Intervention without onsite Cardiac Surgery Backup
}

\author{
Laxman Dubey, ' Sanjib Kumar Sharma, 'Rabindra Bhattacharya, ' Sogunuru Guruprasad, ' Gangapatnam \\ Subramanyam ${ }^{1}$ \\ 'Department of Cardiology, College of Medical Sciences and Teaching Hospital, Bharatpur-10, Chitwan, Nepal
}

Introduction: Mechanical revascularization by percutaneous coronary interventions has now become an established and preferable method of revascularization in patients with acute coronary syndromes. The aim of the study was to identify the clinical indications for percutaneous coronary interventions and in-hospital outcomes of percutaneous coronary interventions in a tertiary-level hospital without onsite cardiac surgery backup.

Methods: This was a prospective descriptive study. All consecutive patients who were admitted for percutaneous coronary interventions, including both primary as well as elective percutaneous coronary interventions, between March 2011 and December 2012 were included in the study.

Results: Total 101 percutaneous coronary interventions were performed. The mean age was $58.9 \pm$ 12.3 years. The most frequent indication was ST-elevation myocardial infarction 72 (71.3\%). Proximal artery stenting were performed in 39 (38.5\%) and the non proximal artery stenting in $62(61.5 \%)$. The outcomes were mortality $5(4.9 \%)$, periprocedural myocardial infarction $2(1.9 \%)$, cardiogenic shock $6(5.9 \%)$, contrast induced nephropathy requiring dialysis in $3(2.9 \%)$, minor complications which were managed conservatively in $13(12.9 \%)$.

Conclusions: Percutaneous coronary intervention was feasible with acceptable complications in a tertiary-level hospital without onsite cardiac surgery backup. ST-elevation myocardial infarction was the major indication and cardiogenic shock was the major complication observed, and non proximal artery stenting was more common than the proximal artery stenting.

Keywords: indication; onsite cardiac surgery; outcomes; percutaneous coronary interventions.

\section{INTRODUCTION}

In 1977, Andreas Gruentzig ${ }^{1}$ had performed the first percutaneous transluminal coronary angioplasty in human, since then percutaneous coronary intervention (PCI) has become a mainstay in the treatment of coronary artery disease (CAD). Around 2,000,000 PCI are being performed every year worldwide with a steady increase. ${ }^{2}$ With the combination of catheter technique, experienced operators and the development of new devices and medications, the procedural outcomes of $\mathrm{PCl}$ have improved and it has now become an established and preferable method of revascularization.

Correspondence: Dr. Laxman Dubey, Department of Cardiology, College of Medical Sciences and Teaching Hospital, Bharatpur-10, Chitwan, Nepal. E-mail: dubeylax@yahoo.com, Phone: 9851123288. 
Our center is a tertiary-level hospital without cardiac surgery backup, which has provided interventional cardiology services since 2011. There are only a few hospitals in Nepal which provide $\mathrm{PCl}$ service, and there is limited data on the outcomes of $\mathrm{PCl}$ in our cohort of patients. Moreover, a limited number of studies have reported favorable outcomes for $\mathrm{PCl}$ in hospitals without onsite cardiac surgery backup. ${ }^{3,4}$ The objective of the present study was to evaluate the indications and procedural complications including in-hospital mortality in a cohort of unselected consecutive patients treated with $\mathrm{PCl}$ since over last two years.

\section{METHODS}

This was a prospective descriptive study. From March 2011 to December 2012, a total of $101 \mathrm{PCls}$ were carried out among them 64 cases were primary and rest 37 were rescue or elective $\mathrm{PCl}$. Medical records of these 101 consecutive patients who had undergone $\mathrm{PCl}$ with stent deployment as a mode of reperfusion were reviewed. Ethical committee had approved for the study. Both written and informed consent were obtained. Patients who had prior $\mathrm{PCl}$ at other hospitals and all lesions treated with plain old balloon angioplasty (POBA) were excluded.

The primary outcome variables of the study were indications for $\mathrm{PCl}$ that included stable angina, unstable angina (UA), Non ST elevation myocardial infarction (Non STEMI), STEMI, and anginal equivalent. The $\mathrm{PCl}$ outcomes included were arrhythmia requiring treatment, post procedure cardiogenic shock, stroke, heart block, contrast induced nephropathy requiring dialysis, minor complications and death. UA was defined as ischemic chest pain at rest within the preceding 48 hours or within the past month (Braunwald class II and III), with ST segment depression and/or T-wave inversion. Non STEMI was diagnosed with ST segment depression and/ or prominent $T$ wave inversion and positive biomarkers of cardiac necrosis (troponin I) in the absence of ST segment elevation or both. Stable angina was defined as both typical exertional chest pain relieved by rest, and an electrocardiographically positive exercise stress test.

STEMI was diagnosed on ECG changes with ST segment elevation, new onset left bundle branch block. Cardiogenic shock was labeled as a clinical state of hypoperfusion, characterized by a systolic blood pressure $<90 \mathrm{~mm} \mathrm{Hg}$ and central filling pressure $>20 \mathrm{~mm} \mathrm{Hg}$. Primary $\mathrm{PCl}$ was defined as the coronary intervention procedure for the treatment of acute STEMI performed in an emergency setting. Arrhythmia requiring treatment, i.e., ventricular tachycardia was diagnosed on three or more QRS complexes of ventricular origin at a rate exceeding 100 beats per min.

$\mathrm{PCl}$ was performed by standard methods. Patients underwent diagnostic angiography followed by $\mathrm{PCl}$ of the infarct-related artery. All procedures were done through right femoral arterial approach with single wall puncture technique, using six French or seven French guiding catheters as appropriate except in three cases where right radial artery route was chosen. The data collected included age, gender, past medical history of hypertension (systolic blood pressure $\geq 140 \mathrm{~mm}$ $\mathrm{Hg}$, and/or diastolic pressure $\geq 90 \mathrm{~mm} \mathrm{Hg}$, and/or on medication), dyslipidemia (fasting cholesterol $\geq 200$ $\mathrm{mg} / \mathrm{dl}$ and/or low density lipoprotein $\geq 130 \mathrm{mg} / \mathrm{dl}$ or on treatment), diabetes (defined as a fasting glucose $>126 \mathrm{mg} / \mathrm{dl}$ and/or on treatment) and smoking; and the final indications and outcome were recorded. $\mathrm{PCl}$ success was defined as achievement of vessel patency to a residual stenosis $<20$ plus normal Thrombolysis in Myocardial Infarction (TIMI) three flow.

Descriptive statistics of different variables of the sample population were computed. Means and standard deviations (SD) were calculated for quantitative variables. Categorical variables reported in percentages for the gender, history of dyslipidemia, diabetes, hypertension and smoking, indications of $\mathrm{PCl}$ and complications were considered. Frequency of indications and complications were noted as the primary outcome of the study. The statistical package for social sciences version 13.0 (SPSS Inc., Chicago, IL, USA) was used for data analysis. $P$ values less than 0.05 were considered to be statistically significant.

\section{RESULTS}

The mean age was $58.9 \pm 12.3$ years, with age range of 30 years to 91 years (Table 1). Of the $101 \mathrm{PCls}$ performed, $24(23.7 \%)$ were carried out in women and $22(21.8 \%)$ in patients over 70 years of age. Past medical history showed diabetes mellitus in 25 (24.7\%) patients, hypertension in 52 (51.5\%), dyslipidemia in $13(12.9 \%)$ and current or former smoking in 60 $(59.4 \%)$ patients. $\mathrm{PCl}$ was done as primary $\mathrm{PCl}$ in 64 $(63.4 \%)$ and elective in $37(36.6 \%)$ cases. Total stents used were 119 and the details of culprit lesion stenting are given in Table 2. Single vessel stenting was done in 88 cases, double vessel stenting in 12 and triple vessel stenting in the same setting was done in one patient. Bare metal stent (BMS) was used in all except in two patients where drug eluting stents were deployed. 


\begin{tabular}{|ll|}
\hline \multicolumn{2}{|c|}{ Table1. Age distribution of the cases. } \\
\hline Age range (years) & $\mathbf{n}=101(\%)$ \\
$30-40$ & $3(2.9)$ \\
$41-50$ & $8(7.9)$ \\
$51-60$ & $38(37.6 \%)$ \\
$61-70$ & $30(29.7 \%)$ \\
$71-80$ & $14(13.8 \%)$ \\
$81-90$ & $7(6.9 \%)$ \\
$>90$ & $1(0.9 \%)$ \\
\hline
\end{tabular}

\begin{tabular}{|llllllll|}
\hline \multicolumn{7}{c|}{ Table 2. Culprit lesion stenting details. } \\
\hline & LM & LAD & Diagonal & LCX & OM & RCA & RI \\
& $(n=1)$ & $(n=56)$ & $(n=1)$ & $(n=19)$ & $(n=2)$ & $(\mathbf{n = 3 8})$ & $(\mathbf{n = 2})$ \\
Ostial & - & 2 & - & - & - & & - \\
Proximal & - & 19 & 1 & 7 & 2 & 15 & 1 \\
Mid & 1 & 33 & - & 9 & - & 16 & - \\
Distal & - & 2 & - & 3 & - & 7 & 1 \\
\hline
\end{tabular}

LM: Left main; LAD: Left anterior descending artery; LCX: Left circumflex artery; OM:

Obtuse marginal branch; RCA: Right coronary artery; RI: Ramus intermedius artery.

The most frequent indication for $\mathrm{PCl}$ was STEMI $(71.3 \%)$ followed by UA/Non STEMI $(17.8 \%)$, stable angina (5.9\%) and anginal equivalent $(4.9 \%)$ patients respectively (Table 3 ). Among the procedural complications of $\mathrm{PCl}$, post-procedural cardiogenic shock in $6(5.9 \%)$, periprocedural $\mathrm{MI}$ in $2(1.9 \%)$, contrast induced nephropathy (CIN) requiring dialysis in $3(2.9 \%)$, minor complications which were managed conservatively in $13(12.9 \%)$ and death in $5(4.9 \%)$ patients was witnessed. There were no occurrences of stroke or transient ischemic attack (Table 4).

Comparing the type of vessel treated there was no significant difference between proximal LAD artery stenting as compared to proximal LCX/ RCA stenting $(38 \%$ vs $39 \%)$ and also the non proximal LAD artery stenting as compared to non proximal LCX/RCA stenting $(62 \%$ vs. $61 \%)$. But the number of non proximal artery stenting was significantly higher as compared to the proximal artery stenting $(62 \%$ vs. $38 \%$ and $61 \%$ vs. $39 \%$ in LAD and LCX/RCA respectively, $(P<0.05)$ (Table 5).

\begin{tabular}{|ll|}
\hline Table 3. Indications for PCI. \\
\hline Indications & $\mathbf{n = 1 0 1}(\%)$ \\
Stable angina & $6(5.9 \%)$ \\
Unstable angina/ Non STEMI & $18(17.8 \%)$ \\
STEMI & $72(71.3 \%)$ \\
Anginal equivalent & $5(4.9 \%)$ \\
\hline
\end{tabular}

Non STEMI: Non ST elevation myocardial infarction; STEMI: ST elevation myocardial infarction; Anginal equivalent includes dyspnea, arrhythmia, dizziness or syncope of unexplained etiology

\begin{tabular}{|ll|}
\hline \multicolumn{2}{|l|}{ Table 4. In hospital clinical outcomes. } \\
\hline Variables & $\mathbf{n = 1 0 1}(\%)$ \\
Periprocedural MI & $2(1.9 \%)$ \\
Post procedural cardiogenic shock & $6(5.9 \%)$ \\
Arrhythmias requiring treatment & $4(3.9 \%)$ \\
CIN requiring dialysis & $3(2.9 \%)$ \\
Stroke & $0(0 \%)$ \\
Minor complications & $13(12.9 \%)$ \\
Death & $5(4.9 \%)$ \\
\hline
\end{tabular}




\begin{tabular}{|llll|}
\hline $\begin{array}{l}\text { Table 5. Proximal and non proximal vessel stenting } \\
\text { details. }\end{array}$ & LAD & LCX and RCA & P value \\
\hline & $(\mathbf{n}=\mathbf{5 6})$ & $(\mathbf{n}=\mathbf{5 7})$ & \\
Proximal & $21(38 \%)$ & $22(39 \%)$ & NS \\
Non Proximal & $35(62 \%)$ & $35(61 \%)$ & NS \\
P value & $<0.05$ & $<0.05$ & \\
\hline
\end{tabular}

MI: Myocardial Infarction; CIN: Contrast induced nephropathy; Minor complications include groin hematoma, chills and rigor, vasovagal reaction, contrast induced nephropathy not requiring dialysis.

\section{DISCUSSION}

The number of $\mathrm{PCl}$ procedures has increased considerably in Nepal in recent years. Till date there are only six hospitals in Nepal that are equipped with a cardiac catheterization laboratory facility, and this number is too small to satisfy the medical needs of patients with CAD. Among them, only three hospitals have onsite cardiac surgery.

$\mathrm{PCl}$ has undergone tremendous growth over the past two decades and become a safe and effective procedure, and also has proven to be superior to thrombolysis for reperfusion. ${ }^{5}$ Initially, $\mathrm{PCl}$ was performed at clinical sites with surgical backup as complication rates and need of urgent surgery were high. With the improvement in catheter technique, experienced operators and the development of new devices, overall complication rates of $\mathrm{PCl}$ are low and emergency cardiac surgery rates resulting from $\mathrm{PCl}$ procedure are at $0.2 \%{ }^{6}$

$\mathrm{Wu}$ and colleagues, ${ }^{7}$ showed in-hospital mortality of $1.8 \%$ while in our study the in-hospital mortality was $4.9 \%$. A slightly higher mortality in our study may be secondary to higher number of patients with STEMI. Among five deaths, one patient died because of massive retroperitoneal bleeding. The patient was an 84-year old female who developed retroperitoneal hematoma after $\mathrm{PCl}$ stenting to the LCX artery. That patient died despite massive blood transfusion. Rest three patients who died had AMI complicated with cardiogenic shock and had multivessel disease. Despite undergoing $\mathrm{PCl}$ stenting to the culprit vessel, they did not improve from cardiogenic shock. One patient died of recurrent ventricular tachycardia which developed immediately after stenting to the LAD artery.

As compared to the Melbourne Interventional Group (MIG) Registry, ${ }^{8}$ in which $38 \%$ patients underwent $\mathrm{PCl}$ for UA/Non STEMI, followed by stable CAD $34 \%$ and STEMI $23 \%$, our study had high proportion of patients with STEMI, i.e., $71.3 \%$, followed by UA/Non STEMI
$17.8 \%$ and stable angina $5.9 \%$. $\mathrm{PCl}$ was done in $4.9 \%$ of patient who presented with anginal equivalent symptoms.

There were more stenting in LAD artery $(n=56)$ as compared to RCA $(n=38)$ and LCX artery $(n=21)$. Management of proximal CAD is important due to the large areas of myocardium that lie downstream of the stenoses. The proximal LAD artery supplies nearly 40$50 \%$ of the total left ventricular myocardium, thus the proximal LAD stenosis could result in ischemia to a large area of myocardium.9,10 Alidoosti and colleagues, ${ }^{11}$ have reported that the outcomes of $\mathrm{PCl}$ in patients with proximal LAD stenosis were similar to patients with proximal LCX/RCA and non proximal LAD stenosis. In our study, there was no difference in number of stenting to the proximal LAD as compared to the proximal LCX/ RCA, however, there was significantly higher number of stenting in the non proximal LAD and LCX/RCA as compared to the proximal parts. This finding showed that non proximal stenting in our study is higher than the proximal artery stenting.

All procedures in our study were successfully completed. In $101 \mathrm{PCl}$ cases, total 119 stents were deployed out of which $98 \%$ were bare metal stents and rest were drug-eluting stents. Peri-procedural $\mathrm{MI}$ was found in $1.9 \%$ of patients, which is significantly less than the other published data $8 \% .^{2}$ At least $5 \%$ of patients who undergo cardiac catheterization experience a transient rise in the plasma creatinine concentration of more than $1.0 \mathrm{mg} / \mathrm{dL}(88 \mu \mathrm{mol} / \mathrm{L})$ due to contrast-induced renal dysfunction. ${ }^{12}$ In our study, CIN developed in seven (6.9\%) patients. Among those who developed CIN, four patients recovered on conservative management, however, three $(2.9 \%)$ patients required hemodialysis.

There are some limitations of our study. This study was performed in a single center and the number of patient included in the study was less. Bare metal stents were used more frequently in our cases because of the financial constrain of the patient and lack of national health insurance facility in this underdeveloped country.

\section{CONCLUSIONS}

The most common indication for PCl was STEMI and non proximal coronary artery stenting was higher than proximal coronary artery stenting. Despite having no cardiac surgery backup, in-hospital mortality and other complications following $\mathrm{PCl}$ were acceptable in our cardiac catheterization laboratory. 


\section{REFERENCES}

1. Gruentzig AR. Transluminal dilatation of coronary artery stenosis. Lancet. 1978;1:263.

2. Smith SC Jr, Feldman TE, Hirshfeld JW Jr, Jacobs AK, Kern MJ, King SB $3^{\text {rd }}$, et al. ACC/AHA/SCAI 2005 guideline update for percutaneous coronary intervention: a report of the American College of Cardiology/American Heart Association Task Force on Practice Guidelines (ACC/AHA/ SCAI Writing Committee to update the 2001 Guidelines for Percutaneous Coronary Intervention). J Am Coll Cardiol .2006;47:216-35.

3. Paraschos A, Callwood D, Woghtman MB, Tcheng JE, Phillips HR, Stiles GL, et al. Outcomes following elective percutaneous coronary intervention without onsite surgical backup in a community hospital. Am J Cardiol. 2005;95:1091-3.

4. Ting $\mathrm{HH}$, Raveendran G, Lennon RJ, Long KH, Singh M, Wood DL, et al. A total of 1007 percutaneous coronary interventions without cardiac surgery: acute and long-term outcomes. J Am Coll Cardiol. 2006;47:1713-21.

5. Keeley EC, Boura JA, Grines CL. Primary angioplasty versus intravenous thrombolytic therapy for acute myocardial infarction: a quantitative review of 23 randomized trials. Lancet. 2003;361:13-20.

6. Lemkes JS, Peels JOJ, Huybregts R, de Swart H, Hautvast R, Umans V. Emergency cardiac surgery after a failed percutaneous coronary intervention in an interventional centre without on-site cardiac surgery. Neth Heart J. 2007;15:173-7.
7. Wu AH, Goss JR, Maynard C, Stewart DK, Zhao XQ. Predictors of hospital outcomes after percutaneous coronary intervention in the community. J Interv Cardiol. 2004;17:151-8.

8. Ajani AE, Reid CM, Duffy SJ, Andrianopoulos N, Lefkovits J, Black A, et al. Outcomes after percutaneous coronary intervention in contemporary Australian practice: insights from a large multicentre registry. Med J Aust. 2008;189:423-8.

9. Mahmarian JJ, Pratt CM, Boyce TM, Verani MS. The variable extent of jeopardized myocardium in patients with single vessel coronary artery disease: quantification by thallium-201 single photon emission computed tomography. J Am Coll Cardiol. 1991;17:355-62.

10. 10. Klein LW, Weintraub WS, Agarwal JB, Schneider RM, Seelaus PA, Katz RI, et al. Prognostic significance of severe narrowing of the proximal portion of the left anterior descending coronary artery. Am J Cardiol. 1986;58:42-6.

11. Alidoosti M, Salarifar M, Zeinali AM, Kassaian SE, Dehkordi MR. Comparison of outcomes of percutaneous coronary intervention on proximal versus non-proximal left anterior descending coronary artery, proximal left circumflex, and proximal right coronary artery: a cross-sectional study. BMC Cardiovasc Disord. 2007;7:7.

12. Tomasso CL. Contrast induced nephrotoxicity in patients undergoing cardiac catheterization. Cath Cardiovasc Diagn. 1994;31:316-21. 